\title{
Vier gedigte uit Brandenburg
}

\section{Auf dem Heimweg}

Zehn Minuten von Zuhause entfernt geraten wir in eine andere Welt. Dort steht Bobrowski auf der Leiter, hämmert am Dach seiner Nebelhütte und schüttelt den Kopf über unsere Frage nach dem Weg vor unseren Füßen. Auf den nixengrünen Hügeln liegt ein Nachmittag, der schon gestorben ist, in seinem Glück vielleicht.

Auch wenn es sie gäbe, Paralleluniversen bedeuten, du kannst denselben Abzweig nicht noch einmal verfehlen. Dieses Mal weiß auch Bobrowski nicht weiter, er wohnt gar nicht hier, und wir müssen es sein, die in kalten Fingern ein armes löchriges Firmament aus glitzernder Pappe halten, du an dem einen, ich am anderen Giebel.

Licht sickert aus dem Garten durch einen, wo zwei mit ihren Schatten gehen und reden, in einen dritten ohne Schatten, und was sie sagen würden, steht als Rauch aus ihren Mündern überm Schnee. Der Alte spuckt Nägel, nickt über den First: Da entlang könnt ihr verschwinden, und wir, Figuren, die der Held einer Komödie erzählt, folgen.

(Geist 2018:n.p.)

\section{'working wood'}

heute früh

wieder, da war es

schon beinahe hell: Holz

unter den Bedingungen der Bucht.

Ächzend, einsilbig, januarklar.

Ich suchte danach, in meiner Sprache, doch es lässt sich nicht hören in ihrem Überfluss an Silben. Arbeitendes Holz ist so hässlich wie wirkendes schief.

Erst im flachen Schlaf knistert, was ich nicht mehr erlebte, der große Petroleumkauf der Teppichweber von Kuyan-Bulak für die Trockenlegung des Sumpfs, dem das Fieber entschwirrte, und die langwierigen Fragen der Leute unterm lodernden Dach an Buddha, ob es wirklich brenne hier oder nicht doch woanders.

\section{Op pad huis toe}

Tien minute van die huis af beland ons in 'n ander wêreld. Daar staan Bobrowski op 'n leer, timmer aan die dak van sy newelige hut en skud sy kop vir ons vraag na die weg vir ons voete. Op die meermingroen heuwels lê 'n namiddag reeds gestorwe, vermoedelik in sy vrede.

Selfs al sou dit bestaan, die eweheelalle beteken nie jy kan 'n afdraai twee keer misloop nie. Hierdie keer het Bobrowski ook nie raad nie, hy woon glad nie hier nie, en dit moet óns wees wat so met koue vingers 'n gehawende uitspansel van skitterkarton omhoog hou, jy by die een gewel, ek by die ander.

Lig syfer van die tuin af deur een, waar twee met hul skadu's geselsend 'n skadulose derde instap, en wat hulle wou sê, kom soos rook by hul monde uit bo die sneeu. Die grysaard spuug spykers, wys met kopknik oor die nok: Verdwyn maar daarlangs. En ons, figure, vertel deur die held in 'n klug, volg.

\section{'working wood'}

vroegdag

weer, toe dit

byna lig is: hout

wat weens die omstandighede in die baai

kreun, eenlettergrepig, Januarie-skerp.

Ek het daarna gesoek, in my taal,

maar kon niks daarvan hoor in die oorvloed

sillabes nie. Hout wat bewerk word, is ewe ontwrig as bewerkte hout wat skeef is.

Eers in ligte slaap knetter dit wat ek reeds deurgemaak het, die matborduurders van Koejan-Boelak se groot petrolaankoop om die moeras te dreineer waaruit die koors gons,

en hul langdradige vrae aan die Boeddha onder die brandende dak:

Brand dit werklik hier en nie iewers anders nie?

\begin{tabular}{|c|c|c|}
\hline & & Authors: Charl-Pierre Naudé ${ }^{1}$ (D), Rentia Bartlett-Möhl² \\
\hline \multirow{6}{*}{ 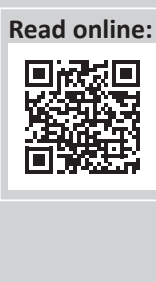 } & \multirow{4}{*}{$\begin{array}{l}\text { Scan this QR } \\
\text { code with your } \\
\text { smart phone or } \\
\text { mobile device } \\
\text { to read online. }\end{array}$} & $\begin{array}{l}\text { Affiliations: }{ }^{1} \text { Department of Afrikaans, Dutch, German and French, Faculty of Humanities, University of the Free State, Bloemfontein, South Africa; } \\
{ }^{2} \text { Private, Johannesburg, South Africa }\end{array}$ \\
\hline & & Corresponding author: Charl-Pierre Naudé, charlpierren@gmail.com \\
\hline & & Dates: Received: 09 July 2019 Accepted: 06 Oct. 2020 Published: 10 Dec. 2020 \\
\hline & & $\begin{array}{l}\text { How to cite this article: Naudé, C-P. \& Bartlett-Möhl, R., 2020, 'Vier gedigte uit Brandenburg', Literator 41(1), a1637. https://doi.org/10.4102/ } \\
\text { lit.v41i1.1637 }\end{array}$ \\
\hline & & Copyright: (c) 2020. The Authors. Licensee: AOSIS. This work is licensed under the Creative Commons Attribution License. \\
\hline & & $\begin{array}{l}\text { Note: The German poems are translated into English with permission from the author, Sylvia Geist. Please see the reference list of the article } \\
\text { for more information. }\end{array}$ \\
\hline
\end{tabular}


Während ich träume,

sie verloren geben zu können, anstatt sie verlieren zu müssen, knarrt es vom Dachstuhl her von Versäumnissen (wieder nicht, noch und noch), lässt die Fensterläden versagen, arbeitet an der Tür, gegen die ich gestern antrat, dass sie nicht mehr schließt, während ich träume, es ist besser als die gelenkige Sprache im Traum,

redet es lange,

nachdem man es schlug,

den Zerfall des Hauses herbei.

(Geist 2018:n.p.)

\section{Die Vermissten}

Zur Erinnerung für das Tier

lassen sie das Licht an.

Sie haushalten nicht,

mit Energie, sie entbehren.

Es jagt, sagen sie sich.

$\mathrm{Zu}$ leicht zu haben,

ist die Büchse erst mal geöffnet,

sind Geflügelgelee und gehäckselte Knochen.

Sie vermissen das Fell, ihre Hände,

feuchtkalt, erschrecken voreinander ohne den Körper,

der ihnen beiden gehörte.

Ihn treibt es unters tropfende Vordach, qualmen, sie in den Garten, ab zum Bach, der zorndick dem Sund zu läuft.

Das gemästete Biest jagt.

In den Daunen fühlen sie seine Sehnsucht nach etwas, das zappeln und bluten kann, sticheln, dann dringt es vor zu ihnen, dringt ein wie Hahnsamen ins Dotter, bevor es zur Schale kommt.

Sie verzichten auf jeden Versuch, es besser zu haben. Die Türen bleiben offen, die Fensterbeete bestrahlt von Watt, brechen sie morgens auf zum Steg.

Er zittert an seinen Krücken, seine Augen schwimmen in Tränen, wenn sie loswatet, sich Stück für Stück entfernt bis aufs Geräusch des Widerstands, den sie dem Wasser bietet, und beide, Kälte und Nähe, sind da.

(Geist 2018:n.p.)

\section{Klärung}

Keinesfalls sei das Schwarz der letzten Gemälde ein Vorbote, so seine Tochter. Ihr Haar ist direkter Nachfahre der späten Palette, ein Strich so satt, dass er bis nach Texas reicht. Wohin es mich zog,
Terwyl ek droom

dat ek iets kan opgee pleks van om dit te moet verloor, knars die dakbalke van nalatighede (nog nie, en nogmaals nie), laat dit die luike ingee, en werk dit in op 'n deur waarteen ek gister geskop het en wat nie meer sluit nie; terwyl ek droom, doen die hout beter as buigsame tale in 'n droom,

en praat dit lank

nadat dit gekap is

oor die verval van die huis.

\section{Die vermistes}

Sodat die dier kan onthou,

los hulle die lig aan.

Hulle leef nie spaarsamig

met krag nie, hulle ontbeer.

Hy jag, vertel hul mekaar.

Te maklik,

dié hoenderkwab met gemaalde been as die blik eers oopgeskroef is.

Hulle mis die pels, hul klamkoue hande skrik vir mekaar sonder daardie lyfie wat hulle gedeel het.

Uitgedryf na die druppende afdakkie rook hy vuriglik, sý in die tuin tot by die stroompie wat woed op pad na die baai.

Die vetgevoerde dier jag.

In die vere vind hulle sy verlange na iets wat kan spartel en bloei, met verwyte, dan dring dit by hulle op soos haansaad wat 'n dooier binnedring voordat die dop vorm.

Hulle laat vaar die pogings om dinge te verbeter. Die deure bly oop, en die vensterbanke straal van die watts as hul soggens na die kaai loop.

Hy bibber op sy krukke, sy oë swem in trane, wanneer sy wadend stuk vir stuk verder raak behalwe vir die geraas van verset wat sy vir die water gee, en beide, die koudheid én nabyheid, daar is.

\section{Verheldering}

Die swart van sy laaste skilderye was beslis geen voorbode, verklaar sy dogter. Haar hare, wat direk uit sy laat palet spruit, is 'n verfstreep só vol en breed dat dit tot in Texas strek. Waarheen dit my trek 
seit ich zum ersten Mal aufbrach vor Tagesanbruch, vierjährig, auf dem eisblauen Sitz in schlafrotem Pullover und in Erwartung, nicht wissend wessen. Eine Kordel hielt die Nacht im Fenster des Fiat

und die Strähnen vom Anfang zusammen. Ich floss ein in den Asphalt und die Wand, den Wald, Amseln zeichneten sich ab im Gedächtnis und dunkelten nach auf den Masten in Texas, das ein Land aus steinaltem

Tannenhonig war, eine Leinwand, die das Schwarz aus den morgentraurigen, formlosen Dingen sog, es schluckte wie geschmolzenen Zucker, einer Kapelle aus Amseln zum Futter, da wo die anfangen in Texas.

(Geist 2018:n.p.) sedert my eerste voordagvertrek:

Vier jaar oud, op 'n ysblou motorsitplek, met my slaaprooi jakkie aan, wagtend op iets, ek weet nie mooi wat nie. 'n Ferweelkoord hou die nag buite die Fiat-venster

en die haarslierte van die begin bymekaar. Ek vervloei in die teer, en die symuur, die woud, merels vergestalt in my geheue en verdonker op die drade in Texas, plek van steenoue

denneheuning, op 'n verfdoek wat die swart uit die oggendtriestige, vormlose dinge suig en afsluk soos lopende suiker, om 'n kapel van merels te voer, by die punt in Texas, waar hulle begin.

\section{Vier gedigte uit Brandenburg}

Vertaal deur Charl-Pierre Naudé en Rentia Bartlett-Möhl

\section{Biografie: Sylvia Geist}

Die digteres Sylvia Geist is in 1963 in Wes-Berlyn gebore en het daar grootgeword. Die gedigte kom uit haar jongste digbundel Fremde Felle (2018, Hanser-Berlyn), wat soos haar ander werk met groot lof en toekennings ontvang is. Sy kan tot die eerste rang van eietydse lewende digters in Duits gereken word. Sy woon in Duitsland se provinsie Brandenburg nie te ver van die Poolse grens af nie. Benewens skrywer is sy in die chemie gekwalifiseer.

\section{Enkele notas by die vertalings}

- Op pad huis toe: Die gedig bring 'n tipiese kontreipad in die oostelike platteland van Duitsland tot lewe. 'Brobowski' is 'n verwysing na die digter Johannes Brobowski (1917-1965). Ná die verdeling van Duitsland in die sestigerjare word Brobowski deur die noodlot 'n burger van Oos-Duitsland omdat hy in die oostelike deel van Berlyn gewoon het.

- 'working wood': Die titel verwys na die klank wat hout maak as dit uitsit en inkrimp. Die gedig vermeld twee gedigte van Bertolt Brecht: 'Die tapytwewers van Koejan-Boelak vereer Lenin' en 'Boeddha se gelykenis van die brandende huis'.

- Verheldering: Hierdie gedig verwys na Kate Rothko, dogter van die kunstenaar Mark Rothko, wat oor haar pa se werk praat. Sy het swart hare en die kleur swart speel 'n rol in haar pa se werk. Die Rothko-kapel in Texas is 'n huldigingsplaats vir Rothko se werk. Die digter het my meegedeel dat sy as kind op vakansies met haar ouers na die woude van Oostenryk per motor gegaan het. Hierdie reise het ten dele deur die beleërde Oos-Duitsland geloop en die pad word in surrealistiese verband gebring met die pad na Texas waar die Rothko-kapel staan.

\section{Reference}

